\title{
REVIEW
}

\section{Quality of Life and its Influencing Factors in Urban Elderly Patients with Chronic Diseases}

\section{Jun Zheng $^{{ }^{*}} \quad$ Hong Zhao $^{2} \quad$ Xinru Wu}

1. Health Center of Air Force Zhengzhou Eastern Suburb Cadres Sanatorium, Zhengzhou, Henan, 450008, China.

2. Hospital of Luoyang Electric Power, Luoyang, Henan 471000, China.

\begin{tabular}{l}
\hline ARTICLE INFO \\
\hline Article history \\
Received: 26 March 2019 \\
Accepted: 28 March 2019 \\
Published Online: 30 April 2019
\end{tabular}

Keywords:

Elderly patients with chronic diseases

Quality of life

Influencing factors

\begin{abstract}
Objective: To analyze and discuss the quality of life of elderly patients with chronic diseases and its influencing factors. The aim of this study was to provide a theoretical basis for targeted intervention of influencing factors of chronic diseases and improvement of the quality of life of patients. Methods: A total of 1000 elderly patients with chronic diseases in our health center were randomly selected as the study subject. Questionnaire survey was conducted by self-designed questionnaire. The SF-36 quality of life scale was used to evaluate their quality of life; and linear regression model was used to explore the relevant influencing factors. Result: The SF-36 score showed that there was a correlation between the six dimensions, including overall health, physiological function, somatic pain, vitality, social function and mental health, and the number of chronic diseases in elderly patients. With the increase of chronic diseases, the scores of each dimension showed a downward trend. Linear regression analysis showed that age, anxiety and poor sleep quality were the main factors affecting the quality of life in elderly patients with chronic diseases. Conclusion: The quality of life of elderly patients with chronic diseases in our city is poor. In community work, targeted nursing and intervention should be given according to the types of diseases suffered by the elderly.
\end{abstract}

vere mental disorders, who are unconscious and unable to communicate properly and express their will, should be excluded. Patients who signed relevant informed consent.

\subsection{Methods}

A face-to-face questionnaire survey of patients was conducted by a uniformly trained investigator using a uniformly formulated questionnaire. The contents of the survey mainly include age, gender, education level, marital status and other basic conditions, and the prevalence

*Corresponding Author:

Jun Zheng,

Health Center of Air Force Zhengzhou Eastern Suburb Cadres Sanatorium, Zhengzhou, Henan, 450008, China;

E-mail: justinzheng@163.com. 
of chronic diseases. The Pittsburgh Sleep Quality Index (PSQI) was used to evaluate the quality of sleep, which was divided into 7 components (0-3 points for each) such as sleep quality and sleep time. The total score was 21 points. The higher the score, the worse the sleep quality was. The anxiety scale and depression scale was used to evaluate the degree of anxiety and depression, each with 20 items (1-4 points for each). Both of total scores are $20-80$ points. The higher the score, the more serious the degree of depression and anxiety is. The SF-36 scale was used to evaluate the quality of life.

\subsection{Statistical methods}

Statistical analysis was performed using SPSS20.0 software. The measurement data was expressed as " $\pm \mathrm{s}$ " and $\mathrm{t}$ test was used. The count data was expressed as percentage $(\%)$, and the $\mathrm{x}^{2}$ test was used. $\mathrm{P}<0.05$ was used as statistical significance.

\section{Results}

\subsection{General Materials and Chronic Conditions of Patients}

Among the 1000 patients, 578 (57.8\%) were male; the youngest was 60 years old, the largest was 91 years old; the female patients had $422(42.2 \%)$. The top five chronic diseases were followed by hypertension in $564(56.4 \%)$, diabetes in $433(43.3 \%)$, coronary heart disease in 532 (53.2\%), chronic bronchitis in $292(29.2 \%)$, and cerebrovascular disease in 217 (21.7\%).

\subsection{Relationship Between Quality of Life and Chronic Diseases}

There were significant differences in 6 dimensions of overall health, physiological function, somatic pain, vitality, social function and mental health among the number of chronic diseases $(\mathrm{P}<0.05)$ (Table 1).

Table 1. Comparison of quality of life in elderly patients with different numbers of chronic diseases $( \pm \mathrm{s})$

\begin{tabular}{|c|c|c|c|c|}
\hline \multirow{2}{*}{ MOS SF-36 } & \multicolumn{3}{|c|}{ Numbers of Chronic Diseases } & \multirow{2}{*}{} \\
\cline { 2 - 4 } & $\begin{array}{c}\text { One chronic } \\
\text { disease }\end{array}$ & $\begin{array}{c}\text { Two chronic } \\
\text { diseases }\end{array}$ & $\begin{array}{c}\geq \text { Three } \\
\text { chronic dis- } \\
\text { eases }\end{array}$ & \multirow{2}{*}{} \\
\hline Overall Health & $72.5 \pm 11.0$ & $63.2 \pm 14.6$ & $47.1 \pm 12.0$ & $<0.01$ \\
\hline $\begin{array}{c}\text { Physiological } \\
\text { Functioning }\end{array}$ & $79.9 \pm 8.9$ & $75.1 \pm 9.1$ & $68.8 \pm 10.2$ & 0.19 \\
\hline $\begin{array}{c}\text { Physical Limita- } \\
\text { tions }\end{array}$ & $73.8 \pm 14.3$ & $72.3 \pm 12.5$ & $46.7 \pm 16.4$ & $<0.01$ \\
\hline Somatic Pain & $78.2 \pm 12.1$ & $67.9 \pm 10.4$ & $51.5 \pm 12.7$ & $<0.01$ \\
\hline Vitality & $81.2 \pm 16.5$ & $77.5 \pm 14.1$ & $64.8 \pm 16.3$ & $<0.01$ \\
\hline Social Function & $79.6 \pm 15.3$ & $71.2 \pm 10.6$ & $55.6 \pm 16.1$ & 0.03 \\
\hline
\end{tabular}


ed in the aspects of physical function, self-care, memory function, social adaptation and overall health. Older people have worse quality of life, which is consistent with previous studies.

There are also some differences in social adaptation, self-care and general health among elderly patients with chronic diseases who have different educational background. This is mainly because patients with lower educational background have lower income and social status, which makes the quality of life of patients on the low side. The elderly patients with chronic diseases who live with their children or husband/wife are better in quality of life, because family members have a more positive impact on patients in emotional. Drinking alcohol is beneficial to the health of the elderly. The elderly patients with chronic diseases who live with their children or husband and wife are better in quality of life, because family members have a more positive impact on patients in emotional aspects. Drinking alcohol have certain benefits for the health of the elderly.

In conclusion, chronic diseases have a serious impact on the quality of life of the elderly. Patients with different chronic diseases also have different quality of life, but their overall health status is relatively poor. In the community health service center, the role of "health gate- keeper" should be brought into full play, so as to improve the health management of the elderly and prevent the occurrence of chronic diseases in the elderly, so that the adverse effects of chronic diseases on the elderly can be greatly reduced. In terms of physiology, the elderly can be encouraged to participate in more appropriate social activities, and the diet should be healthy. On the psychological side, the elderly can be helped to learn to correctly treat some psychological problems caused by age and chronic diseases, so that physical and mental health can be maintained. In terms of emotions, the elderly should be helped to adjust their negative emotions timely and correctly, and be encouraged to participate in social activities properly, and maintain a good mood.

\section{References}

[1] Luo ZQ. Effect of Psychological Nursing on the Psychological Status of Elderly Patients with Chronic Diseases. China Medicine and Pharmacy 2016,6(18):122-124.

[2] Yang CM, Yan YH, Yang XH, Zeng ZQ, Chen J. Analysis of Chronic Disease Status of Community Elderly Residents and their Demand for Home Care Services. Journal of Chengdu Medical College 2016,11(04):504-506. 